Fourth International Conference on Sustainable Construction Materials and Technologies http://www.claisse.info/Proceedings.htm

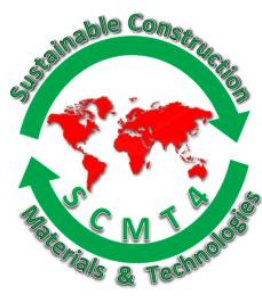

SCMT4

Las Vegas, USA, August 7-11, 2016

\title{
Evaluation of Fire Damage Distribution of Concrete by X-Ray Computed Tomography
}

\author{
Takayuki Fumoto $^{1 a}$, Satoru Mizuno ${ }^{1 b}$, and Mitsuo Ozawa ${ }^{1 c}$ \\ ${ }^{I}$ Department of Civil and Enviromenrtal Engineering, Faculty of Science and Engineering, Kindai \\ University, 3-4-1 Kowakae, Higashiosaka, JAPAN. ${ }^{1 a}$ Email: < fumoto@ civileng.kindai.ac.jp >, \\ ${ }^{1 b}$ Email: < sac.mizu11138@gmail.com >, ${ }^{1 c}$ Email: <ozawa@gunma-u.ac.jp >.
}

\begin{abstract}
The physical and chemical transformations that take place when concrete is exposed to high temperatures result in the deterioration of its mechanical properties. As a result of these changes, concrete gradually or quickly loses its mechanical strength and durability. The effects of high-temperature exposure manifest themselves in the form of surface cracks, spalling and disintegration, which render concrete structures unserviceable. To identify the depth at which the concreate change its qualities, a phenolphthalein solution is sprayed to concrete cores taken from the concrete construction. Also, a method to measure the salt penetration depth in the concrete cores immersed in salt water is suggested. The two-dimensional boundary position is measured by those mothods. However, the continuous changes in the qualities in the depth direction is unclear. We used an X-ray computed tomography (CT) method for the concrete cores obtained from the structure. The continuous changes in qualities in the core would be measured by analyzing X-rayCT images. Therefore, our purpose of this study is to explore the applicability of X-ray CT to evaluation of damage distribution inside concrete damaged by heating. First, small mortar specimens heated at different temperatures were measured by the X-ray CT method. The results show that the qualities after the heating can be evaluated clearly using the CT values. Then, the concrete test specimens of $100 \mathrm{~mm}$ in diameter were heated from the upper surface. The change of the CT values in the depth direction was measured, and the correlation between the change of the CT values and the internal temperature of the specimen was high. Moreover, the relationship between the results and the carbonation depth or the salt penetration depth was examined.
\end{abstract}

\section{INTRODUCTION}

When concrete structures are heated at high temperature, the temperature is continually lower in correspondence with the depth from the surface of the structure [Neville 1996]. Therefore, the deterioration degree of the concrete changes in the depth direction. For example, the pulling strength, the bond strength of the reinforcement and the substance permeation resistance would become lower as the depth from the construction surface becomes deeper [Neville 1996, Ozawa 2012, 2014, 2015]. If the degree of deterioration can be evaluated, the deterioration state of the heated concrete, a appropriate repairing method and the depth to which repairing is needed will be determined more clearly.

Including the geotechnology and the construction material, the $\mathrm{X}$ ray $\mathrm{CT}$ apparatus was used for estimating the dynamical and physical properties of the material. The X ray CT method has an advantage 
that the continuous change of deterioration of the material in the depth direction can be estimated. Therefore, the X ray CT method will be able to associate the degree of deterioration with the temperature given to material in detail. However, the industrial X ray CT apparatus has not yet been provided enough. For the future, it is necessary to clarify the utility value of the X-rays CT method.

Therefore, we estimated the continuous deterioration in the heated concrete in the depth direction with Xray CT [Fumoto 2013] . The X-ray CT is a technique to estimate the three-dimensional distribution of a $\mathrm{X}$ ray absorption coefficient in an imaging range. The $\mathrm{X}$-ray absorption coefficient is generally expressed with a CT value. The CT value is a relative $\mathrm{X}$ ray absorption value in a supposed case in which the CT value of air is -1000 and that of water is 0 [Japanese Society of Radiological Technology 2011]. The CT value is influenced by an $\mathrm{X}$ ray irradiation condition, a material density and an atomic number.

In this study, we show applicability of X-ray CT to evaluation of continuous deterioration distribution in the heated concrete [Fumoto 2014]. First, the relationship between the apparent density and the CT value of the small mortar specimens heated at predetermined temperatures was investigated as fundamental research. Next, the CT value distribution, the carbonation depth and the salt penetration depth were compared in the depth direction of the concrete specimen heated from the upper surface to $973 \mathrm{~K}$.

\section{EXPERIMENTAL INVESTIGATION FOR MORTAR}

Materials and test methods. Mortar was prepared from water, high-early strength portland cement and silica sand with a small mixer. The $\mathrm{W} / \mathrm{C}$ is $50 \%$ and the $\mathrm{S} / \mathrm{C}$ is 3.0. The mixed mortar was placed into polyvinyl chloride pipes with an inside diameter of $20 \mathrm{~mm}$. Six specimens were made with a height of approximately $60 \mathrm{~mm}$. The test specimens were removed from the polyvinyl chloride pipes on the following day. After removed, the all test specimens were cured in water at $293 \mathrm{~K}$ for 14 days. The five cured test specimens were dried at $378 \mathrm{~K}$ for 24 hours in order to prevent the explosion of the test specimens. Four dried test specimen was heated to a temperature of $473,573,673$ or $773 \mathrm{~K}$ at a speed of approximately $5 \mathrm{~K} / \mathrm{min}$ in an electric furnace. The heating was stopped immediately after the temperature reached the target temperature. The test specimens were taken out from the electric furnace when the temperature in the electric furnace reached around $323 \mathrm{~K}$. Figure 1 shows changes of the temperature in the furnace. The heating treatment was carried out at about 16 days material age.

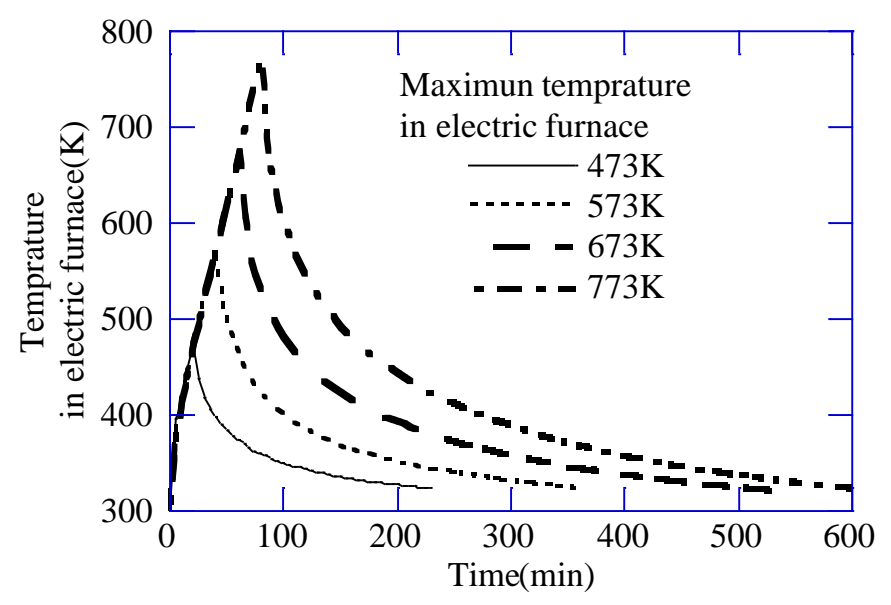

Figure 1. Temperature variation in electric furnace

The test specimens after cured in the water at $293 \mathrm{~K}$ and heated at 378-773 K were scanned by an X-ray computed tomography (CT) apparatus [Fumoto 2013]. The scanning was carried out for material ages from 16 to 19 days. On the other hand, the dimensions of each test specimen were measured in a vernier 
caliper, and the volume of the test specimens were calculated from the dimensions. Dividing a weight of specimen by the measured volume got an apparent density of the specimen. With the X-ray CT apparatus as shown in figure 2, the test specimens were scanned at a tube voltage of $180 \mathrm{kV}$ and a tube current of 60 uA. Three-dimensional images of test specimens were reconstructed with cube voxels of a side length of $0.1226 \mathrm{~mm}$. A frequency distribution of a CT value of 5 to $55 \mathrm{~mm}$ in the height of the three-dimensional image of the test specimen was calculated using commercial image analysis software.

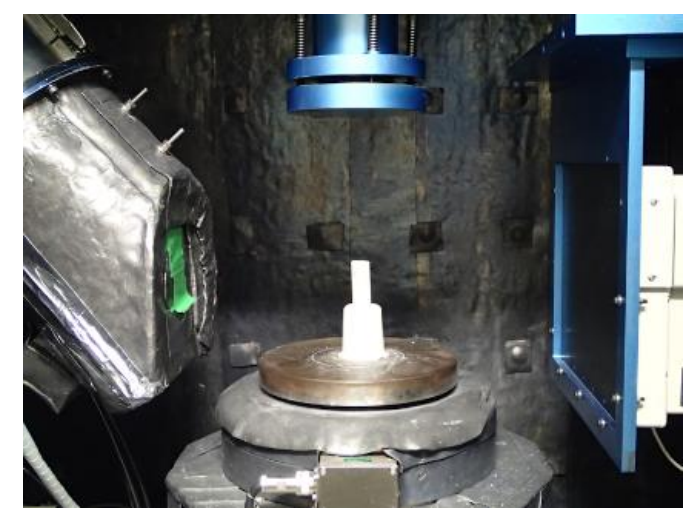

\section{Figure 2. State of a mortar specimen scanned by X ray CT}

Results and discussion for mortar test. The CT value distribution before and after heating the test specimen at $773 \mathrm{~K}$ was compared as shown in figure 3 . Here, the vertical axis is the ratio of the voxel number indicating each CT value to the total voxel number. As a result, the shape of the CT value distribution became an asymmetrical mountain type. The reason of asymmetry is the presence of air bubbles of a few millimeters in diameter. In this study, the most frequent value of the CT value distribution was used as a representative CT value of the test specimen, because the mean value and the intermediate value of the $\mathrm{CT}$ value distribution were influenced by the air bubbles.

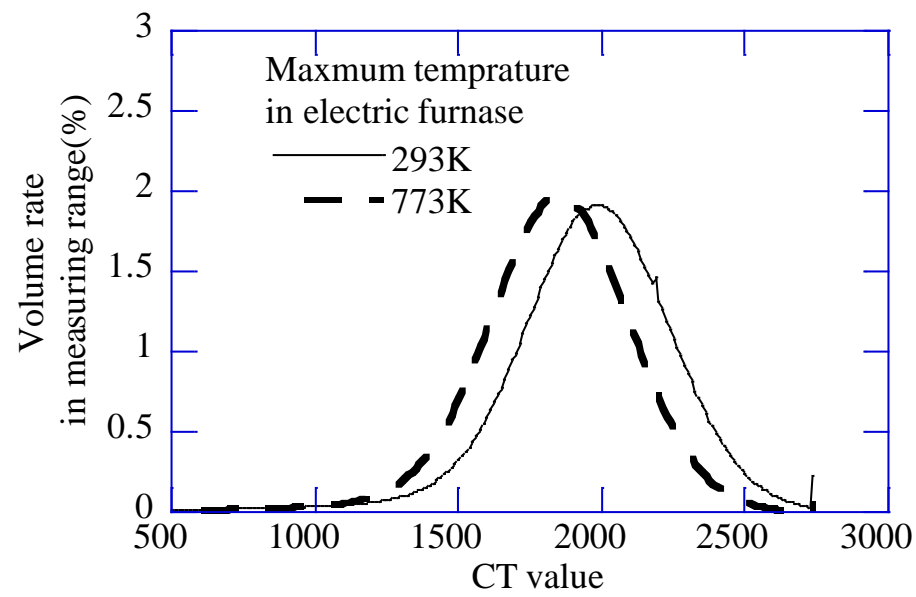

Figure 3. CT value distribution in mortar specimen

Figure 4 shows the relationship between the maximum temperature at which the test specimens were heated and the apparent density of the test specimens. The apparent density after curing in the water at $293 \mathrm{~K}$ was $2.28 \mathrm{~g} / \mathrm{cm}^{3}$. The apparent density of the test specimen after drying at $378 \mathrm{~K}$ fell to $2.15 \mathrm{~g} / \mathrm{cm}^{3}$. The apparent density was approximately $2.12 \mathrm{~g} / \mathrm{cm}^{3}$, even if the heating temperatures increased to $573 \mathrm{~K}$. However, the apparent density fell to $2.06 \mathrm{~g} / \mathrm{cm}^{3}$, if the heating temperature was more than $673 \mathrm{~K}$. 
These changes of the apparent density suggest physical and chemical changes of the cement paste. For example, it is generally known that the apparent density was dropped by evaporation of free water in the cement paste at 373-573 K [Neville 1996]. The decomposition of the hydration products and the occurrence of the microcracks will cause the decrease of the apparent density when the heating temperature is more than $673 \mathrm{~K}$, because calcium hydroxide in the cement paste dehydrates at approximately $673 \mathrm{~K}$. These tendencies are also seen in figure 4 .

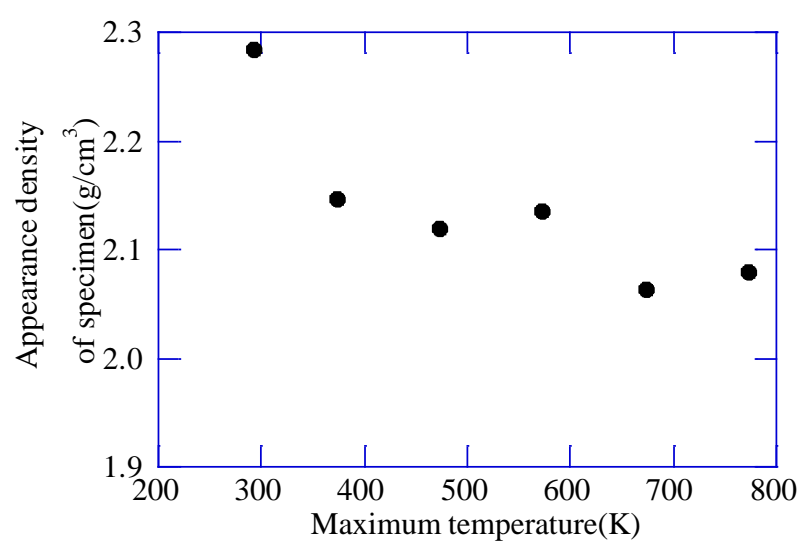

\section{Figure 4. Relationship between maximum temperature and apparent density of specimen}

Figure 5 shows the relationship between the heating temperature and the decrease in the CT value in the test specimen before and after the heating. The decrease in the CT value was 75 , if the test specimen was dried at $378 \mathrm{~K}$ after curing in the water. The decrease in the CT value fell to 87.5 when the specimen was heated at $473-573 \mathrm{~K}$. The decrease in the CT value was changed from 125 to 112 when the test specimen was heated at $673 \mathrm{~K}$ or more. Therefore, this tendency of the CT value was the same as the apparent density.

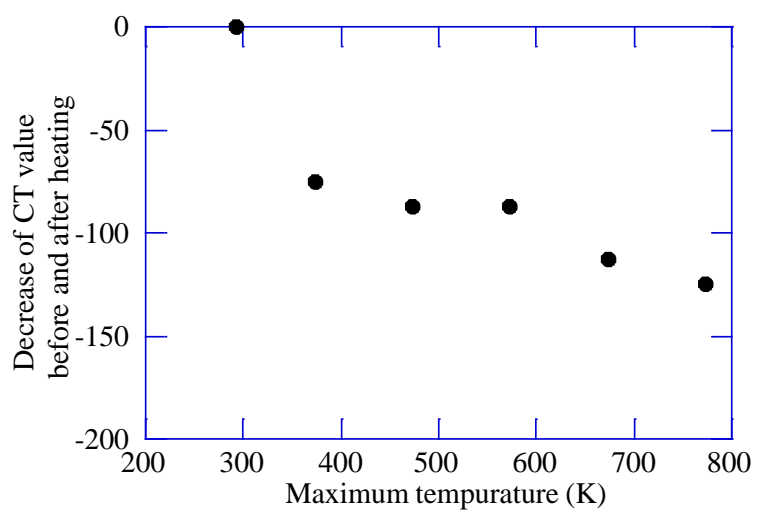

Figure 5. Relationship between maximum temperature and decrease value before and after heating

Figure 6 shows the relationship between the apparent density of the test specimen and the degree of the CT value reduced by the heating. The relationship was linear. Its correlation coefficient was 0.987. These results show a possibility that the decrease in the CT value of the specimen before and after the heating showed the degree of deterioration of mortar caused by the heating. In other words, the results indicate that the CT value is affected by the physical and chemical changes of the cement paste. 


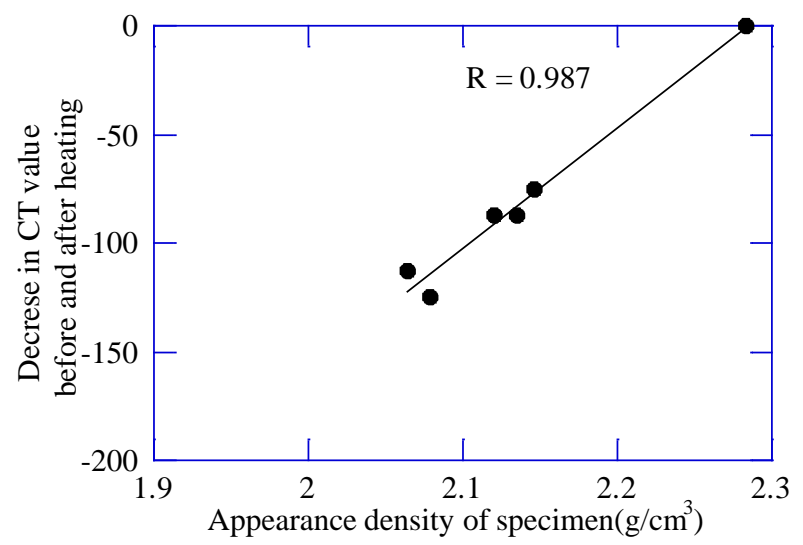

\section{Figure 6. Relationship between apparent density of specimen and difference in CT value before and after heating}

\section{EXPERIMENTAL INVESTIGATION FOR CONCRETE}

The deterioration degree of the specimen heated uniformly was evaluated. The continuous deterioration degree in a specimen was evaluated in this chapter when the upper face of the specimen was heated.

Materials and test methods. Tap-water, high-early strength portland cement, mountain sand, crushed stone, a polycarboxylic superplasticizer and a deforming agent were mixed with an omni-mixer to prepare the concrete. The density in saturated surface dry condition was $2.60 \mathrm{~g} / \mathrm{cm}^{3}$, and the absorption of the mountain sand was $2.03 \%$. The density in saturated surface dry condition was $2.56 \mathrm{~g} / \mathrm{cm}^{3}$, and the absorption of the crushed stone was $2.04 \%$. Table 1 shows the mix proportions of the concrete. The mixed concrete was placed into 14 cylinder molds of $100 \mathrm{~mm}$ in diameter and $200 \mathrm{~mm}$ in height.

The all specimens removed from the cylinder molds after one day were cured in the water at $293 \mathrm{~K}$ for 20 days. After curing, the compressive strength and the static elastic coefficient of the concrete were tested with three specimens by following JIS A 1108 and JIS A 1149. The five specimens were cured in the water again. The upper surfaces of six specimens were heated at 5 degrees per minute to $973 \mathrm{~K}$ in an electric furnace with a system as shown in figure 7. The temperature in the electric furnace was held at $973 \mathrm{~K}$ for 1 hour and the electric furnace was cooled by natural cooling. In this heating system, the upper surface of each specimen was placed in the hole at a bottom of the electric furnace and the temperature in the electric furnace was increased. A thermal insulation material was placed around the side of the specimen. As a result, only the upper surface of the specimens was heated.

Six thermocouples were embedded in one of the six specimens at $0,20,40,60,100,140$ and $180 \mathrm{~mm}$ in depth from the upper surface. These thermocouples were used to measure internal temperatures in the specimen. At a month later from heating the specimens, the five heated specimens and the five cured specimens were scanned with an X-ray CT apparatus. The CT value distribution in specimen of each $10 \mathrm{~mm}$ in depth were calculated with the three dimensional image which was gotten by X ray CT method. The most frequent value of the CT value distribution was used as representative CT value for each depth of $10 \mathrm{~mm}$. After scanning, the $1 \%$ solution of phenolphthalein was sprayed onto a splitted surface of a heated specimen. The depth which was not colored was used as a carbonation depth. Also, after immersing two of the five heated specimens into the $1 \%$ solution of salt water, a silver nitrate aqueous solution was sprayed onto a splitted surface of each immersed specimen. The depth which was colored by silver was used as a salt penetration depth. 
Results and discussion for concrete test. Figure 8 shows the temperature history in the electric furnace. The temperature in the electric furnace increased with the speed of approximately $5 \mathrm{~K}$ per minute. The temperature reached $973 \mathrm{~K}$ in approximately 130 minutes. After holding $973 \mathrm{~K}$ for 60 minutes, the heating was stopped. After 300 minutes, the door of the electric furnace was opened by $15 \mathrm{~mm}$. The door was opened fully after 330 minutes. The concrete specimen was taken out from the electric furnace after 360 minutes.

Figure 9 shows the maximum internal temperature in the depth direction of the specimen. The internal temperature in the specimen was approximately $663 \mathrm{~K}$ at $40 \mathrm{~mm}$, approximately $563 \mathrm{~K}$ at $60 \mathrm{~mm}$, approximately $463 \mathrm{~K}$ at $100 \mathrm{~mm}$ and approximately $373 \mathrm{~K}$ at $170 \mathrm{~mm}$ in depth from the surface of the specimen. The deterioration degree at each position in the depth direction will be influenced by the maximum internal temperature at each position. The results of figure 9 are used for discussion of this study.

figure 10 shows the $\mathrm{CT}$ value distribution in the depth direction of specimens before and after heating. In a CT value distribution of the depth direction of each five test specimens before and after heating, the deviation from the mean value of five specimens was approximately 50. The difference in the mean CT value was from 80 to 160 before and after the heating. Therefore, the CT value was clearly different before and after heating. The deeper the depth from the upper face, the smaller the difference of the CT value before and after the heating.

Table 1. Mixture proportion

\begin{tabular}{|c|c|c|c|c|c|c|}
\hline \multirow{2}{*}{$\begin{array}{l}\mathrm{W} / \mathrm{C} \\
(\%)\end{array}$} & \multirow{2}{*}{$\begin{array}{l}\text { Air content } \\
(\%)\end{array}$} & \multirow{2}{*}{$\begin{array}{l}\text { s/a } \\
(\%)\end{array}$} & \multicolumn{4}{|c|}{ Unit content $\left(\mathrm{kg} / \mathrm{m}^{3}\right)$} \\
\hline & & & Water & Cement & Fine aggregate & Superplasticizer \\
\hline 55 & 5 & 48 & 277 & 504 & 1438 & 0.745 \\
\hline
\end{tabular}

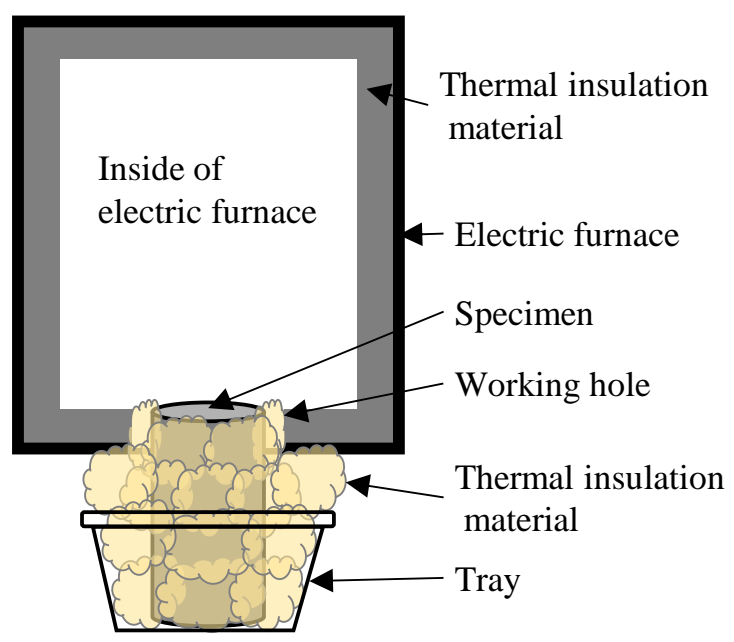

Figure 7. Heating system in this study 


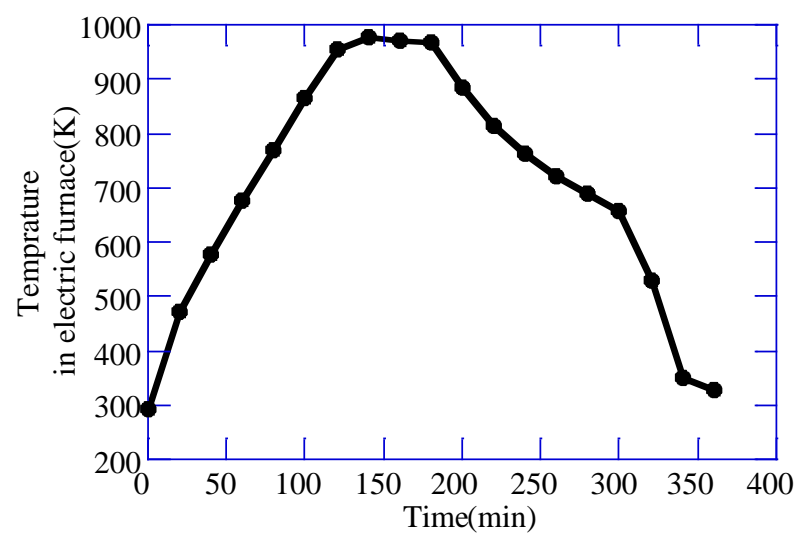

Figure 8. Temperature history in electric furnace

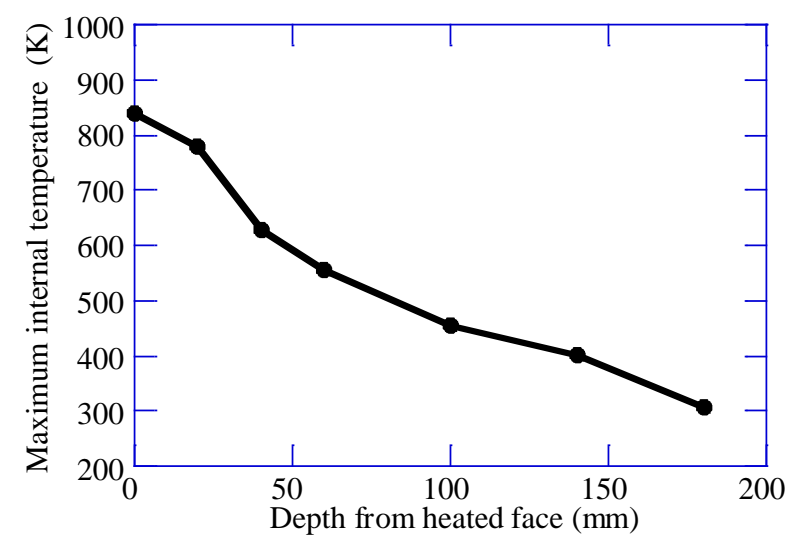

Figure 9. Relationship between depth from heated face and maximum internal temperature

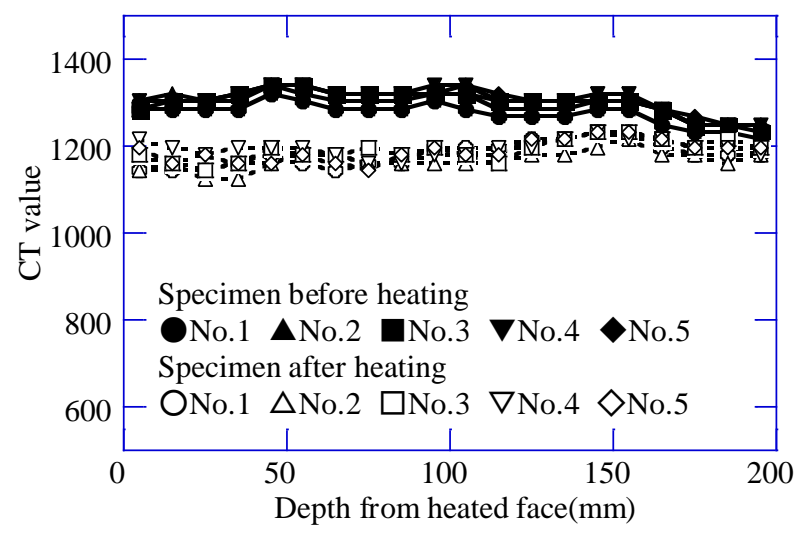

Figure 10. CT value distribution in depth direction

Figure 11 shows the CT value decrease distribution in the depth direction of the specimen. These plots indicate the difference in the mean CT value among three test specimens from which the maxium and the minimum are removed. The decrease in the CT value was around 160 from the upper surface to $55 \mathrm{~mm}$ in depth. The decrease in the CT value became gradually small from 55 to $105 \mathrm{~mm}$ in depth. After $115 \mathrm{~mm}$ 
in depth, the decrease in the CT value decreased sharply. At $145 \mathrm{~mm}$ in depth, the decrease in the CT value became gradually small again. These changes may indicate the physical and chemical changes of the cement paste as shown in figure 6 . Then, the relationship between the change of the CT value and the internal temperature, the carbonation depth or the salt penetration depth was investigated.

Figure 12 shows the relationship between the decrease in the CT value due to the heating and the maximum internal temperature. The internal temperature at each depth were estimated with Fig .9. The decrease in the CT value was 53-90 at 422 from $295 \mathrm{~K}$. The decrease in the CT value sharply increased when the maximum temperature increased from 435 to $492 \mathrm{~K}$. The cause of this tendency will be evaporation of the water. After that, the decrease in the CT value gradually changed until the temperature is $573 \mathrm{~K}$. The decrease in the CT value was approximately $150-160$ for heating at $573-793 \mathrm{~K}$. A calcium hydroxide in the cement paste dehydrates at approximately 673K [Neville 1996]. When the CT value is $150-160$, a part of calcium hydroxide may begin to dehydrate.

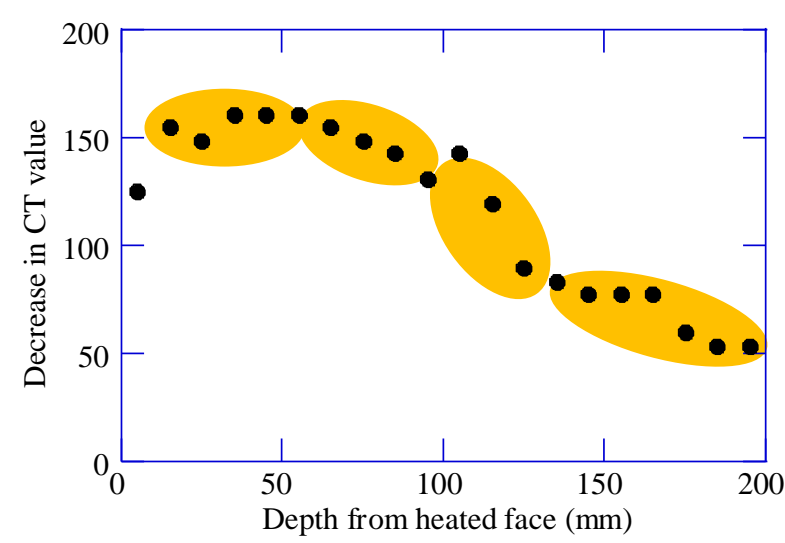

Figure 11. Decrease in CT value in depth direction

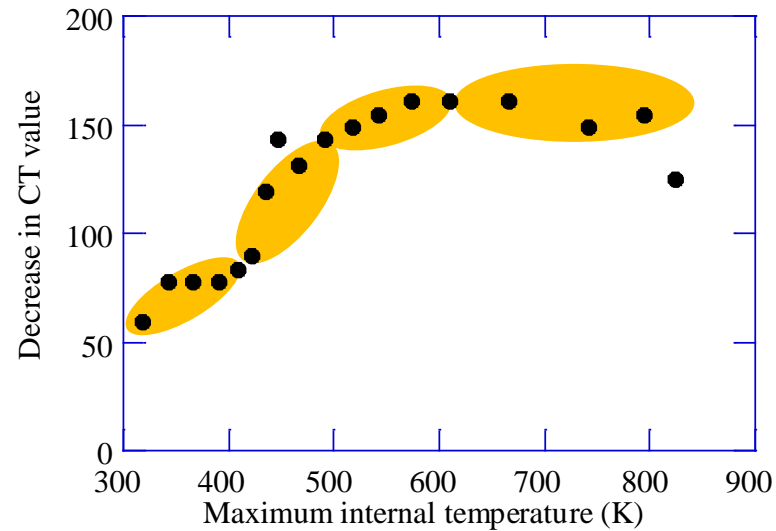

Figure 12. Relationship between maximum internal temperature and decrease in CT value

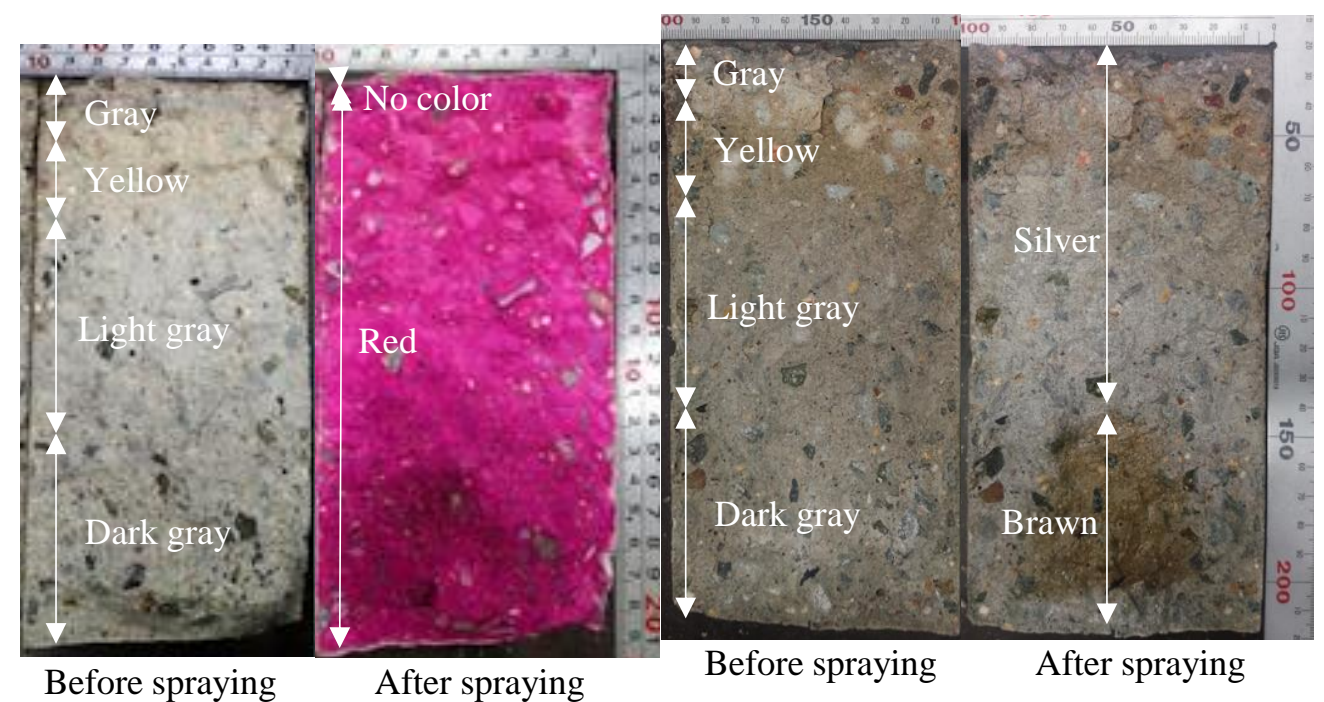

(a) Phenolphthalein water solution

(b) Silver nitrate water solution

Figure 13. Section of test specimen after heating and results from spraying phenolphthalein water solution or silver nitrate water solution 
Figure 13(a) shows the carbonation depth in the specimen. The color of the test specimen section changed in the depth direction after heating. The color of the test specimen section was gray from the upper face to $15 \mathrm{~mm}$, thin yellow at $14-61 \mathrm{~mm}$, light gray at 57-124 mm and strong gray at 124-200 mm in depth. The changes of color will show the water evaporation and the dehydration of calcium hydroxide. The After spraying with phenolphthalein solution, the uncoloring depth became $1.1 \mathrm{~mm}$. Figure 13(b) shows the salt penetration depth in the specimen. The depth colored silver in the heated test specimen was $127 \mathrm{~mm}$ from the heated upper surface. This depth was the point where the maximum temperature reached around $422 \mathrm{~K}$ in Fig 9.

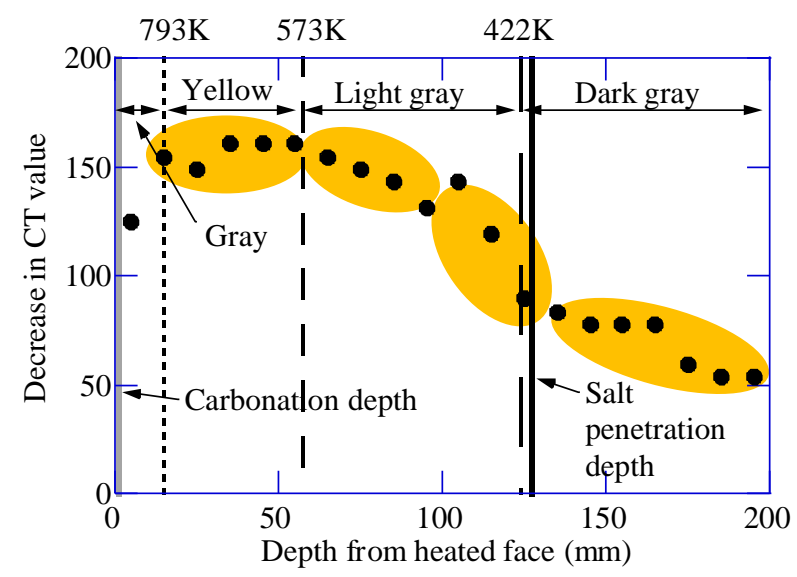

\section{Figure 14. Comparison between decrease in $\mathrm{CT}$ value in depth direction and some spraying test result}

Figure 14 shows the results of spraying the phenolphthalein water solution and the silver nitrate water solution in addition to the results shown in figure 9. Because the heating temperature was low, the relationship between the carbonation depth and the decrease in the CT value was not clear. The carbonation depth indicates that the calcium oxide produced by dehydrating the calcium hydroxide reacted with carbon dioxide in the atmosphere.

On the other hand, the color change point in the section of the test specimen was related with the change point of the decrease of the CT value. In addition, the salt penetration depth was approximately equal with the border where the CT value decreased gradually. The causes of these relations are not only dehydration of the cement hydrate and the free water but also the occurrence of micro cracks.

Thus, the change of the decrease in the CT value would be related with the change of properties of the cement paste. In the future, we would like to clarify the relationship between the decrease in the CT value and the physical and chemical change of the heated cement paste. Accordingly, with the X-ray CT method, an appropriate repairing method and the depth to which repairing is needed will be determined more clearly.

\section{CONCLUSION}

In this study, the relationship between the apparent density and the CT value of the small mortar specimens heated at predetermined temperatures was investigated as fundamental research. Next, the CT value distribution, the carbonation depth and the salt penetration depth were compared with the depth direction of the concrete specimen heated from the upper surface to $973 \mathrm{~K}$. The results are summarized below. 
1) The apparent density of the heated test specimen of $20 \mathrm{~mm}$ in diameter was related with the decrease in the CT value. The deterioration degree of the specimen heated uniformly was evaluated. The result indicates that the CT value is affected by the physical and chemical change of the cement paste.

2) A history of the maximum temperature is closely related with the decrease in the CT value when the upper face of the test specimen of $100 \mathrm{~mm}$ in diameter was heated. The continuous deterioration degree in a specimen was evaluated, when the upper face of the specimen was heated.

3)The change point in the depth direction of the decrease in the CT value is related with the color change in the specimen and the salt penetration depth.

In the future, the relationship between the decrease in the CT value and the physical and chemical change of the heated cement paste will become clear.

\section{REFERENCES}

Japanese Society of Radiological Technology (2011). "CT imaging technique.” $2^{\text {nd }} E d .$, Ohmsha.

Ozawa, M., and Morimoto, H. (2014)."Effects of various fibres on high-temperature spalling in highperformance concrete,." Construction and Building Materials, (71), 83-92.

Ozawa, M., Kamata. R., and Rokugo. K. (2014).”Steel Ring-Based Restraint Of HSC Explosive Spalling In High Temperature Environments,T. Tanibe", Journal of Structural Fire Engineering, 5(3), 239-250

Ozawa, M., Bo, Z., Uchida, Y. and H. Morimoto. (2014)."Preventive Effects of Fibers on Spalling of UFC at High Temperatures, Journal of Structural Fire Engineering", 5(3), 229-238

Ozawa, M., Uchida, S., Kamada, T. and Morimoto, H., (2012).”Study of mechanisms of explosive spalling in high-strength concrete at high temperatures using acoustic emission", Journal of Construction \& Building Materials, (37), 621-628

Ozawa, M. and Tsukagoshi, S. (2015).“Chloride Penetration Resistance of High-Strength Concrete with Synthetic Fiber after Fire Exposure", Proceeding of International Conference on the Regeneration and Conservation of Concrete Structures (RCCS)

Fumoto, T., (2013).“Development of A New Industrial X ray CT System and Its Application to Compression Test of Polymer Concrete", Journal of JSCE, Division E2, 69(2), 182-191(in Japanese)

Fumoto, T., Mizuno, S., and Ozawa, M. (2014) "Fundamental Study of Presumption of Damage Area in Heated Mortar by X rays CT" Proceedings of the Concrete Structure Scenarios, JSMS, 14, 351-356.

JIS A 1108, (2060). "Method of test for compressive strength of concrete." JICS, 16 pages

JIS A 1149,(2010)." Method of test for static modulus of elasticity of concrete." JICS, 10 pages

Neville A. N. (1996).”Properties of Concrete." $4^{\text {th }}$ Ed., Prentice Hall. 